\title{
The Aggregate Technology And Contractionary Effects: An Empirical Estimation
}

\author{
Anyalezu, Nkem Kirk Guthlac, The University of Phoenix, USA
}

\begin{abstract}
Two identifying techniques were used to examine the effects on employment (or hours worked) following a technological innovation at the aggregate level in the United Kingdom's (U.K) economy for the period 1970-2007. In addition, special attention was given to the treatment and/or the definition of hours worked, particularly the debate on level and first differenced hours. Thus, in primarily utilizing the Bank of England dataset, no significant evidence of contractionary effects in the U.K private business economy was found, which contrasts with some recent studies based on the USA post-war II private business economy.
\end{abstract}

Keywords: technology shocks; hours; contractionary effects; real business cycles; TFP; VAR

\section{INTRODUCTION}

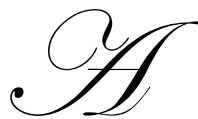

number of recent studies indicated some evidence of contractionary effects in the UK economy, as well in the US post-war II private business economy, following a technological innovation. Notably among these studies are Gali (1999), Khan and Tsoukalas (2006; KT hereafter). In the Gali paper was the highlighting of estimates of the decomposition of productivity and hours into technology and nontechnology components. Furthermore, it implies that the estimated conditional correlations of hours and productivity were negative for technology shocks and positive for non-technology shocks. Gali, therefore, argued that the results were difficult to reconcile with a conventional RBC interpretation of business cycles but, on the other hand, are consistent with a simple model with monopolistic competition and sticky prices.

In addition to the above, Khan et al (2006) demonstrated that after a neutral technology shock, hours worked declined in a persistent manner in the UK. They argued that the responses were robust based on measures of labour input, level versus differenced hours in the vector autoregressive (VAR), small and large VARS, long versus medium run identification, and neutral versus investment specific technology shocks. They even attributed the large negative correlation between labour productivity and hours as the source of the responses. Equally, the assumption is that models with nominal price stickiness, low substitutability between domestic and foreign consumption, and investment specific shocks would be more appropriate in interpreting the short run effects of technology shocks. Thus, KT's (2006) conclusion on the findings was that technology shock might only have a small role as the driving force behind the UK business cycle.

The way hours worked was examined and is defined and implemented in the estimations, as well as its impact on the outcome. This is necessary because RBC models generally regard technology as an important source of economic fluctuations and, consequently, the perception of its effect on employment as expansionary. Following Basu, Fernald and Kimball (2004; BFK hereafter) model and the Gali (1999) approach in evaluating the predictions of the RBC model to positive technology shocks, it is acknowledged that the possibility of aggregate productivity growth before this is product market's imperfect competition. Further insights are in BF (2002) and KT (2006). For example, in the BFK model, when technology improves upon impact, input use falls while output changes very marginally. There are few studies, such as Kiley (1998), Gali (1999), Francis and Ramey (2002), and Basu, Fernald \& Kimball (BFK) (2004), that have came up with results indicating that positive technology shock may reduce total 
hours worked in the short run. This, of course, would be an important finding if it can be confirmed. However, in Chang and Hong (2006), the effect on hours varied across industries, with some showing a reduction and others indicating a rise in hours. Shea (1999) found an increase in input use, especially labour in the short run. The BFK result only contradicts the prediction of real business cycle models of technology improvements being expansionary, that is, both inputs and output increasing instantaneously. Furthermore, a standard one-sector real business cycle (RBC) model would not fit into the model because of the view of expansionary effects due to technology innovations.

There is also the assumption that inputs and outputs tend to rise instantaneously. Francis and Ramey (2001), as well as Vigfusson (2002), regard this view as consistent with the RBC models. Thus, a sticky-price approach could fit to solve the problem as it predicts that 'when technology improves, input use and investment demand would decline in the short term, including output'. Standard RBC model predictions suggest that both the employment of capital and labour will rise in the short run when technology improves, while other macroeconomic models behave to the contrary. In terms of the implications for RBC models, the findings from the various literatures discussed above are inconsistent with standard parameterisations of frictionless RBC models. For instance, the BFK results seems to be in line with the predictions of DGE models with sticky prices, illustrated using the quantity theory and demand for money, with a fixed supply of money and sticky prices.

In this paper, two different techniques were used to investigate the response of hours after technology shocks and for evidence of contractionary effects at the aggregate level in the UK. In contrast with the other studies mentioned above, BEID data were used for the empirical estimations, whereas Gali made use of the US and OECD quarterly labour force statistics while Khan et al was based on simulated data.

\section{Approaches To The Model}

The first of these methods is the direct measurement of technology, or usually referred to as the growth accounting approach. The second approach adopts the bivariate structural vector autoregressive model (BSVAR) technique. In both methods, the assumption is that industries possess a gross output production function represented as:

$$
Y_{i}=F^{i}\left(A_{i} K_{i}, E_{i} H_{i} N_{i}, M_{i}, T_{i}\right)
$$

where ${ }^{Y_{i}}$ represents the gross output, $K_{i}$ the capital stock, $N_{i}$ denoting employees, $M_{i}$ the intermediate inputs (that is, energy and materials), $H_{i}$ represents hours worked per employees, $E_{i}$ denotes the effort per worker and $A_{i}$ capital utilization rate or the capital's workweek. The terms $E_{i} H_{i} N_{i}$ form the total labour input $L_{i}$. The capital stock, together with the number of employees, is assumed quasi-fixed, but firms can also alter their intensity of inputs use. The term $F^{i}$ is the industry's production function, which is homogeneous of arbitrary degree $\gamma_{i}$ in total inputs. Where $\gamma_{i}$ is greater than one, it means that the industry has increasing returns to scale, thereby reflecting overhead costs, decreasing marginal cost, or both, while the term $T_{i}$ denotes the industry's technology.

\section{Technology Estimation}

The first step here is to establish the aggregate technology estimation. Therefore, utilizing Hall's (1990) cost minimization approach, output growth is related to the growth rate of inputs. Thus, the first order condition yield is the essential output elasticities or, in other words, the weighted growth of each input corrected for imperfect competition and technological improvements. Furthermore, for any industry $i$ with variable $J$, the $\Delta j$ was 
defined as its logarithmic growth rate $\ln \left(J_{t} / J_{t-1}\right)$ inputs as $\Delta x_{i}$, thus enabling the definition of growth in output y as:

$\Delta y_{t}^{i}=\mu^{i} \sum_{j=1}^{n} s_{t}^{i, j} \Delta x_{t}^{i, j}+\Delta t_{t}^{i}$

where, ${ }^{i}$ represents each industry mark up, $s^{i, j}$ the share of inputs $j(1, \ldots, n)$ in industry $i$,s gross output and $\Delta t^{i}$, the Solow residuals or technology. The industry level gross output technology shock $\Delta t_{t}^{i}$ aggregated using a weighted sum scheme. In the aggregation, each industry carrying the weight of its nominal share denoted as $w_{t}^{i}$ in total (nominal) value added of $\mathrm{n}$ industries as:

$\Delta t=\sum_{i=1}^{n} w_{t}^{i} \frac{\Delta t_{t}^{i}}{1-\hat{\mu}^{i} s_{t}^{i m}}$

where $\hat{\mu}^{i}$ is the estimated average industry mark up, while $s_{t}^{i m}$ represents the share of materials in industry $i_{\text {at a }}$ given time $t$ period. Therefore $\frac{1}{1-\hat{\mu}_{t}^{i} s_{t}^{i m}}$ transforms the estimated gross output technology shocks into value added shocks. In addition, we correct for work effort and capacity utilization in (2) by introducing growth in hours in the model:

$$
\Delta y_{t}^{i}=\mu^{i} \sum_{j=1}^{n} s_{t}^{i, j}\left[\Delta x_{t}^{i, j}\right]+\beta^{i} \Delta h^{i}+\Delta t_{t}^{i}
$$

Hours per employee growth $\beta^{i} \Delta h^{i}$ entered twice in the equation. This is because it is also in the observed input growth $\Delta x_{t}^{i}$ (examples available in BFK, 2004, or Burnside et al, 1996. The term $\Delta t_{t}^{i}$ denotes the industry technology, while $\beta^{i}$ recognizes all the composite parameters in the coefficient that multiplies the term $\Delta h^{i}$ and, in effect, controls for capital and labour use. The aggregation in equation (3) enables the composition of aggregate technology shock. The next step is the productivity estimation.

\section{Productivity Estimation}

The computation of aggregate productivity growth came as the residual of the difference between aggregate output and input growth rates. In other words, it is the estimated difference between aggregate value-added $\Delta v$ and the share-weighted growth in primary inputs, hence the definition as:

$\Delta p=\Delta v+s_{l} \Delta l+s_{k} \Delta k$

where $S_{k}$ and $S_{l}$ are the shares of capital and labour in output defined as the cost of capital or labour in total value added. The shares need not sum to one, thereby making it distinct to Solow residuals. The terms $\Delta l$ and $\Delta k$ denotes, growth in aggregate capital and labour stocks. Therefore, aggregate productivity growth is as follows: 


$$
\begin{aligned}
& \Delta p=(\mu-1) \sum_{i=1}^{N} \sum_{j=1}^{n} w^{i} \frac{s_{t}^{i, j}}{1-s_{t}^{i, m}}\left[\Delta x_{t}^{i, j}\right]+\mu\left(R^{K}+R^{L}\right)+R_{m}+R_{\mu}+\Delta t \\
& \mu=\sum_{i=1}^{N} w^{j} \frac{s_{t}^{i, m}}{1-s_{t}^{i, m} \mu_{t}^{i}}
\end{aligned}
$$

where ${ }^{\mu}$ denotes aggregate steady-state mark-up weighted by the nominal shares of industry $i$ in $\mathrm{N}$ industries.

From equation 4 came the estimation of the industry mark up $\mu_{t}^{i}$. The terms $\mathrm{R}$ represent resource allocation coming from capital, labour, intermediate goods and imperfect competition, respectively, in equation (6). The first two terms can be obtained as residuals, whilst the last two can be estimated. Finally, equation (6) implies that with perfect competition and no reallocation terms, growth in productivity and technology would be equal.

\section{The BSVAR Step}

Turning now to the BSVAR model approach, productivity and hours estimated decomposition into technology and non-technology components were related. The RBC model, as explored by Kydland and Prescott (1982) and the subsequent extensions, attributes the majority of aggregate fluctuations observed in the post-war U.S. economy as being consistent with the competitive equilibrium of a neoclassical growth model augmented with a labour-leisure choice and exogenous technology shocks. It emphasizes shocks to technology as the main force behind economic fluctuations.

The Gali (1999) approach, on the other hand, has drawn some support; for example, Khan and Tsoukalas (2006) while Christiano, Eichenbaum and Vigfusson (CEV, 2003) all used aggregate technology series computed as in BFK (2002) to show a rise in hours after technology shock. A possible contentious issue relates to the small sample bias and weakness of long run restrictions in identifying technology shocks since non-technology shocks can have permanent impacts on labour productivity; for example, (Khan et al (2006), Faust and Leeper (1997), Uhlig (2004), Erceg et al (2005) and Christiano et al (2005). The other issue is the role of investment specific versus neutral technology shocks as in Fisher (2005 and 2006). For further insight, reference the Gali and Rabanal (2004) study. The prediction of RBC models focuses on the high positive correlation between hours and productivity, especially on shifts in the labour demand schedule caused by technology shocks together with an upward sloping labour supply. The Gali stylized model provided an alternative perception to the productivity - hour's anomaly that deviated from the basic RBC model paradigm.

\section{The BSVAR Model Framework}

The BSVAR model is henceforth commenced model on the premises of labour market dynamics in a sticky price and variable labour efforts (the Keynesian Economics). In other words, a monetary model with a monopolistic competition, sticky prices and variable labour efforts approach was taken. The hypotheses assumption is that technology and monetary shocks are the two prime exogenous factors. The identification restriction process employs three assumptions. The first assumption is that output is determined in line with a homogeneous of degree one, strictly concave, aggregate production function expressed as:

$$
Y_{t}=F\left(K_{t}, T_{t}, L_{t}\right)
$$

where $Y_{t}$ denotes the output, $K_{t}$ and $L_{t}$ represent the effective capital and labour input services used, respectively. The above equation permits for the possible inclusion of the unobservable variations in the utilization rate of inputs of capital and labour. The term $T_{t}$ represents an exogenous technology parameter following a stochastic process with a unit root. 
The second identification restriction assumption is that the capital-labour ratio, measured in efficiency units, $K_{t} / T_{t} L_{t}$ follows a stationary stochastic process. Therefore, if ${ }^{r_{t}}$ represents the return on physical capital, the profit maximization is given by the following expression:

$$
r_{t}=\frac{F_{k}\left(\frac{K_{t}}{T_{t} L_{t}}, 1\right)}{\mu_{i}}-\partial
$$

where $\mu_{i}$ denote mark-up and $\partial$ is the depreciation rate. Therefore, the capital-labour ratio will be stationary whenever the sequence of returns $\left\{r_{t}\right\}$ is stationary.

Finally, the third assumption relates to the effective labour input ${ }_{t}$, which is a homogeneous of degree one function of hours $N_{t}$ and efforts $U_{t}$, thus:

$L_{t}=g\left(N_{t}, U_{t}\right)$

The efforts per hour $U_{t} / N_{t}$ follows a stationary stochastic process and homogeneity required if effective labour input is proportional to hours whenever effort per hour is constant. Therefore, from equations (8) to (10), the

expression for measured labour productivity is represented as

$$
P_{t}=\frac{Y_{t}}{N_{t}}=\frac{Y_{t}}{L_{t}} \frac{L_{t}}{N_{t}}=T_{t} F\left(\frac{K_{t}}{T_{t} L_{t}}, 1\right) g\left(1, \frac{U_{t}}{N_{t}}\right) \text { and }
$$
in $\log$ form as:

$$
p_{t}=t_{t}+\xi_{t}
$$

Under these three assumptions, $\xi_{t} \equiv \log F\left(K_{t} / T_{t} L_{t}, 1\right) g\left(1, U_{t} / N_{t}\right)$ and stationary, hence, making equation (11) crucial for the identification of technology shocks. Thus, using the bivariate structural vector autoregressive (BSVAR) model, the conditional comovement's estimation is possible. In addition, this would allow equation (11) to identify the restriction that only technology shocks might possess a permanent effect on the level of productivity as well as complying with RBC models and/or models with nominal price rigidities.

The computation of the conditional correlations of hours and productivity variations came from the impulse response coefficients of the structural moving average (MA) representation. An example can be found in Gali (1996), Baxter and King (1993), Shapiro and Watson (1988), and Blanchard and Summers (1986). This approach does not require the usual assumptions necessary to construct Solow residual-based measures of technology shock, such as time varying mark ups, capital utilization and corrections for labour hoarding. In terms of the drawbacks with the model as theorized by Gali, arguably said, it does not adequately satisfy the requirement for an endogenous growth model, where all shocks affect productivity in the long term, as well as in standard model when there are permanent shocks to the tax rate on capital income. 


\section{The Specification And Conditional Correlation Estimators}

The assumption is that the observed variations in $\log$ productivity $\left(p_{t}\right)$, or $p_{t}=\ln \left(\frac{Y}{L}\right)$ and $\log$ hours $\left(n_{t}\right)$, originates from two exogenous disturbances; namely, technology and non-technology shocks. They are, in addition, assumed to be orthogonal to each other and their impact propagates over time through unspecified mechanisms. Therefore, the vector $\left[\Delta p_{t}, \Delta n_{t}\right]_{\text {is }}^{\prime}$ an expression of a possible infinite distributed lag of technology and non-technology shocks, and in a matrix form, is:

$$
\left[\begin{array}{c}
\Delta p_{t} \\
\Delta n_{t}
\end{array}\right]_{=}\left[\begin{array}{l}
C^{11}(L) C^{12}(L) \\
C^{21}(L) C^{22}(L)
\end{array}\right]\left[\begin{array}{c}
\varepsilon_{t}^{z} \\
\varepsilon_{t}^{m}
\end{array}\right] \equiv C(L) \varepsilon_{t}
$$

where $\left\{\varepsilon_{t}^{z}\right\}$ and $\left\{\varepsilon_{t}^{m}\right\}$ represent technology and non-technology shocks. The orthogonal assumption, with a standard normalization, indicates $E \varepsilon_{t} \varepsilon_{t}^{\prime}=1$. The identifying restriction for the unit root of productivity is from technology shocks relation to $C^{12}(1)=0$, with the matrix of long run multipliers $C$ (1) constrained to the lower triangular. In addition, $\mathrm{C}(1)$ is the cumulated effect of $C^{11}(L)$. The integration of both productivity and hours are of the order one and, as such, it may be necessary to differentiate the variables to achieve stationarity.

The results to these effects are shown in Table 2. In addition, equation (12) also contains the consistent estimates of the coefficients of $\mathrm{C}(\mathrm{L})$ as a function of the estimated parameters of a reduced-form VAR for $\left[\Delta p_{t}, \Delta n_{t}\right]^{\prime}$. The estimate for $\mathrm{C}(\mathrm{L})$ is set in the impulse response coefficients. Having set the parameters for the reduced form VAR, and establishing the imposed restrictions, we have the expression for the estimate of conditional correlations as:

$$
\rho\left(\Delta p_{t}, \Delta n_{t} / i\right)=\frac{\sum_{j=0}^{\infty} C_{j}^{1 i} C_{j}^{2 i}}{\sqrt{\operatorname{var}\left(\Delta p_{t} / i\right)} \operatorname{var}\left(\Delta n_{t} / i\right)}
$$

where $i=z, m$, while $\operatorname{var}\left(\Delta p_{t} / i\right)=\sum_{j=0}^{\infty}\left(C_{j}^{1 i}\right)$ and $\operatorname{var}\left(\Delta n_{t} / i\right)=\sum_{j=0}^{\infty}\left(C_{j}^{2 i}\right)$ are conditional variances of productivity growth and hours growth. This will eventually tend to infinite. With respect to stationarity, we therefore performed robust diagnostic checks, including standard procedures of the ADF unit root test. The tests are helpful in determining the choice of variables to utilize in the estimations.

\section{A 5-Variable Model}

In this section, we look for evidence to determine the robustness of the estimates and, as such, the estimation of a higher dimensional (5-variable) VAR model. This allows for four orthogonal non-technology shocks. The data used in the specification of the model include data on money, interest rates, prices, productivity and labourinput series used in the bivariate model. The measure of the stock of money for the five variable models is denoted as $\mathrm{m}$. In the estimation, the real growth in M4 was used instead of M0. The reason is M4 has a longer series than

M0. In any case, there are no effects to the results by this choice of variable. The price measure $p_{x}$ is the log of the consumer price index CPI. The nominal interest rate $r$ is the three-month Treasury Bills. In the estimation, both the real interest rate and the inflation rate are entered in levels. In the estimation of the 5-variable model, both the real 
interest rate and the inflation rate were specified in levels and can be justified because there are no theoretical requirements that they must be differenced.

\section{Data Analysis}

In the model, the measure of aggregate technology change $\Delta t_{t}$ contrasted with aggregate productivity growth $\Delta p$. Initially, technology change was estimated at disaggregated level and then aggregate. The main variables were gross output, value added, capital, labour, and intermediate inputs. The BEID capital input computation came from the services of seven assets, of which three are ICT (computers, Software and communications equipment). Each industry's intermediate input is an aggregate of purchases from all other industries and from imports. The labour input is measured by hours worked, but with an adjustment for quality change derived from aggregate data. The dataset construction is consistent with the national accounts, both in nominal and real terms. It is also consistent with the 2002 Blue Book. An important principle behind the BEID dataset is that industry outputs are measured gross, so that proper account can be taken of the contribution of intermediate input.

Data was obtained for the instruments used from SPIRI, Jenkins defence, OECD, and the Bank of England. The other instruments used are Oil from OPEC \& WDS_IEA (crude oil spot prices) and Political based on the periods the Conservative Party or Labour Party is in power. Equally, I used the capital shares $\mathrm{s}_{\mathrm{k}}$ computed by the Bank of England for each industry by constructing a series for required payments to capital following Hall (1990) and BF (2002).

Different maintained assumptions about the stationarity of hours per capita can lead to different outcomes. In Figures 1a \& 1b, per capita hours exhibit a stationarity trend, thus the definitions of hours worked used in the estimations were carefully examined. Following the models approach, hours worked were defined in four different ways; namely:

- $\quad$ CBH: total hours worked divided by the total workforce

- $\quad$ CBPH: total hours worked divided by a measure of the civilian population

- $\quad$ CPH: Average total hours per week worked divided by the civilian population

- $\quad$ CPHRS: Average hours worked divided by the workforce

As shown in Figures 1a and 1b, it does not matter which hour is used; it will still yield the same result. The UK hours data used are trending downward, while US hours for the Gali study is not trending. In addition, the US hours are not stationary, but the UK hours are trend stationary and robust. The trend and cyclical of the four different definitions are of the same pattern.

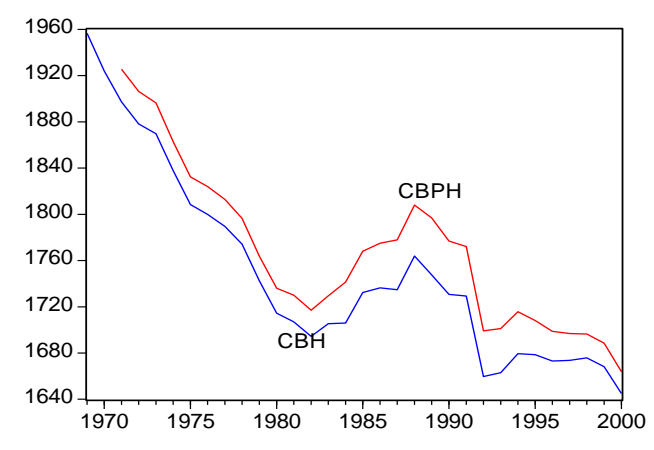

Figure 1a: UK Stationarity - Hours 


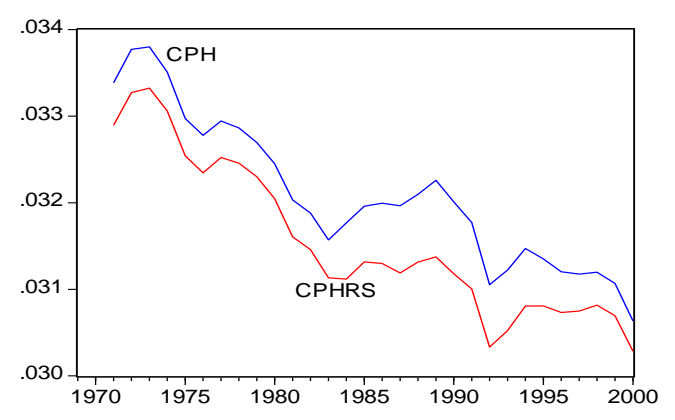

Figure 1b: Stationarity - Hours

The estimated structural VAR for labour input and productivity measures use the UK quarterly data for the period 1970:Q1 - 2006:Q4. The two alternative labour input series are the log of employed civilian labour force denoted as $n_{e}$ and the Log of total employee hours represented as $n_{h}$. The representations for the two alternative time series for $\log$ productivity are $p_{e}$ and $p_{h}$, respectively. The constructions are as the difference between log (GDP); that is, $\mathrm{y}$ and the corresponding labour input measures $n_{e}$ and $p_{e}$ (log of employed civilian labour force and productivity). The other forms are $n_{h}$ and $p_{h}$ (total employee hours worked). Therefore, productivity is $\left(\lg d p-n_{e}\right)$ and $\left(\lg d p-n_{h}\right)$. The Hodrick-Prescott Filter (HPF) estimation applies to each component of employment and productivity. First differences were used, as well as de-trended variables, since they yield the same results as the de-trended ones.

\section{THE EMPIRICAL FINDINGS AND RESULTS}

\section{The Growth Accounting Method}

The results indicate the aggregate effects of technology shocks, estimated as an appropriately weighted average of industry regression residuals, using a 3SLS method in the estimations for the level series. With a control for utilization, both productivity and technology co-moves much closer. Utilization implies that firms are employing factors fully. Table 1 provides a summary of the means and standard deviation of TFP from OLS equation regression estimation. For the private business economy, the standard deviation of technology is 0.03 percent per year compared to the 0.02 percent standard deviation of TFP; a variance of 0.01 percent is low. It is also a slightly similar result for hours. As for manufacturing, the standard deviation of technology is 0.026 percent per year compared to 0.031 percent of TFP; a variance of 0.01 percent per year is high. The reduction in variance is because of the decrease in positive co-variance across industries, consistent with business cycle factors, common demand shocks that induce positive correlation changes in utilization and TFP across industries. 
Table 1: Summary Of The Mean And Standard Deviation Of TFP

\begin{tabular}{|l|l|l|l|}
\hline \multirow{2}{*}{ Solow Residual } & & Private Economy & Manufacturing Economy \\
\hline \multirow{2}{*}{ Purified Residual } & Mean & 0.014 & 0.011 \\
\cline { 2 - 4 } & Std. Deviation & 0.020 & 0.031 \\
\hline \multirow{2}{*}{ Hours } & Mean & 0.014 & 0.017 \\
\cline { 2 - 4 } & Std. Deviation & 0.031 & 0.026 \\
\cline { 2 - 4 } & Mean & 0.014 & 1.183 \\
\hline
\end{tabular}

Notes: U.K Sample period is 1969 - 2000. The purified technology is from aggregating residuals for the industries. Also included is the growth in hours per worker to control for unobserved utilization. The industry Domar weights are $w_{i} /\left(1-s_{m i}\right)$, where $w_{i}$, is the value added weight and $S_{m i}$ is the share of intermediate inputs in output.

Table 2: Regressions On Current And Lagged Technology

\begin{tabular}{|c|c|c|c|c|c|c|c|c|c|}
\hline \multirow{2}{*}{$\begin{array}{c}\text { Dependent Variable } \\
\text { (growth rate) }\end{array}$} & \multicolumn{5}{|c|}{$\underline{\text { Regressors }}$} & \multirow[b]{2}{*}{$\begin{array}{c}\text { Cum. } \\
\text { Effects }\end{array}$} & \multirow[b]{2}{*}{$R^{2}$} & \multirow[b]{2}{*}{ S.E } & \multirow[b]{2}{*}{ D-W } \\
\hline & $\Delta t$ & $\Delta t(-1)$ & $\Delta t(-2)$ & $\Delta t(-3)$ & $\Delta t_{(-4)}$ & & & & \\
\hline \multicolumn{10}{|l|}{ Private } \\
\hline \multirow[t]{2}{*}{ Output } & 0.252 & 0.011 & 0.039 & -0.199 & -0.139 & \multirow[t]{2}{*}{-0.036} & \multirow[t]{2}{*}{0.27} & \multirow[t]{2}{*}{0.020} & \multirow[t]{2}{*}{1.72} \\
\hline & $(0.167)$ & $(0.164)$ & $(0.156)$ & $(0.329)$ & $(0.178)$ & & & & \\
\hline \multirow[t]{2}{*}{ Input } & 0.546 & 0.466 & 0.295 & 0.322 & 0.407 & \multirow[t]{2}{*}{2.036} & \multirow[t]{2}{*}{0.311} & \multirow[t]{2}{*}{0.027} & \multirow[t]{2}{*}{1.52} \\
\hline & $(0.260)$ & $(0.245)$ & $(0.231)$ & $(0.224)$ & $(0.225)$ & & & & \\
\hline \multirow[t]{2}{*}{ Hours/utilisation } & -0.037 & -0.011 & 0.011 & -0.029 & -0.064 & \multirow[t]{2}{*}{-0.13} & \multirow[t]{2}{*}{0.467} & \multirow[t]{2}{*}{0.005} & \multirow[t]{2}{*}{2.06} \\
\hline & $(0.047)$ & $(0.041)$ & $(0.040)$ & $(0.042)$ & $(0.043)$ & & & & \\
\hline \multirow[t]{2}{*}{ Employment } & -0.051 & -0.021 & 0.132 & -0.172 & -0.192 & \multirow[t]{2}{*}{-0.304} & \multirow[t]{2}{*}{0.569} & \multirow[t]{2}{*}{0.013} & \multirow[t]{2}{*}{1.97} \\
\hline & $(0.116)$ & $(0.101)$ & $(0.105)$ & $(0.119)$ & $(0.103)$ & & & & \\
\hline \multirow[t]{2}{*}{ TFP } & -0.878 & 0.081 & 0.054 & -0.309 & -0.038 & \multirow[t]{2}{*}{-1.09} & \multirow[t]{2}{*}{0.69} & \multirow[t]{2}{*}{0.018} & \multirow[t]{2}{*}{1.99} \\
\hline & $(0.158)$ & $(0.242)$ & $(0.136)$ & $(0.143)$ & $(0.149)$ & & & & \\
\hline Manufacturing & & & & & & & & & \\
\hline Output & 1.061 & 0.015 & -0.437 & -0.024 & 0.098 & 0.713 & 0.81 & 0.014 & 1.93 \\
\hline & $(0.146)$ & $(0.149)$ & $(0.142)$ & $(0.142)$ & $(0.121)$ & & & & \\
\hline Employment & 0.164 & 0.277 & 0.055 & -0.133 & -0.104 & 0.259 & 0.61 & 0.013 & 1.81 \\
\hline & $(0.154)$ & $(0.151)$ & $(0.159)$ & $(0.160)$ & $(0.122)$ & & & & \\
\hline TFP & 0.153 & -0.161 & -0.291 & 0.071 & 0.003 & -0.225 & 0.32 & 0.013 & 1.88 \\
\hline & $(0.184)$ & $(0.178)$ & $(0.191)$ & $(0.209)$ & $(0.137)$ & & & & \\
\hline Input & -0.035 & -0.027 & 0.012 & 0.031 & 0.013 & -0.006 & 0.99 & 0.001 & 1.61 \\
\hline & $(0.017)$ & $(0.015)$ & $(0.016)$ & $(0.013)$ & $(0.012)$ & & & & \\
\hline Hours/Utilisation & 0.027 & 0.035 & 0.029 & -0.046 & -0.060 & -0.015 & 0.50 & 0.005 & 1.54 \\
\hline & $(0.054)$ & $(0.057)$ & $(0.053)$ & $(0.052)$ & $(0.048)$ & & & & \\
\hline
\end{tabular}

Notes: Each of the rows in table 2 represents a separate OLS regression of the variable shown in growth rates on the current value plus four lags of estimated technology growth, plus a constant term. The constant terms are not included in the table. The standard error is the parentheses in brackets. Sample adjustment: $1974-2000$. I made corrections for serial correlations in the estimations. The values of the DW-statistic showed evidence of serial correlations, and therefore require correction, by using lags of the dependent variables. The corrections however lowered the powers of the regressions coefficients.

Table 2 highlights the results of the estimated regression to technology shocks $\Delta r$. The first row indicates the response with output growth changes, which is small on impact and negative after a one-year lag. The second row is hours/utilization. The third row is the total observed inputs (cost-share weighted growth in capital and labour). In current technology, the effect is more on the manufacturing economy than it is on the private business economy. Furthermore, the recovery or the cyclical fluctuation is swifter in the manufacturing sector than it is in the private business sector. It is a similar result on TFP, especially on the manufacturing. In terms of the impact-effect on hours or utilization when technology improves, it is negative and insignificant. The impact on hours is a small decline after one period (or year) for the private business economy, but it recovers a little and positive in the second 
period, but insignificant, and then went into contraction in the fourth period. As for the economic implications, it implies that the initial response of labour input during a recovery reflects increased intensity. In other words, existing employees work longer hours and harder. As the recovery progresses, rising labour input hours, in this case, reflects primarily new employment rather than increased intensity.

The column with "cumulative effect" in Table 2 is an aggregation of the shocks for that particular variable. For the private economy, both input and output showed a rise on impact following positive technology shocks, while hours, employment, and TFP showed a decline, or negative sign. For the manufacturing sectors, only inputs have a negative sign on impact following a positive technology change, even though the decline is insignificant. The rise of input on the private economy is significant and positive. Table 3 shows the list of sectors that comprise the U.K private business economy - the SIC classifications. Table 4 is for the manufacturing sectors of the U.K economy only. The term $\mu$ denotes mark-up.

Table 3: Sectoral Estimated Mark-Ups For The U.K Private Business Economy

\begin{tabular}{|c|c|c|}
\hline No. & +2 & SIC 92 \\
\hline 2 & Oil \& Gas & 11,12 \\
\hline 3 & Coal \& Mining & $10,13,14$ \\
\hline 4 & Manufacturing Fuel & 23 \\
\hline 5 & Chemical \& Pharmaceuticals & 24 \\
\hline 6 & Non-Metallic Mineral Products & 26 \\
\hline 7 & Basic Metals \& Metal Goods & 27,28 \\
\hline 8 & Mechanical Engineering & 29 \\
\hline 9 & Electrical Engineering \& Electronics & $30,31,32,33$ \\
\hline 10 & Vehicles & 34,35 \\
\hline 11 & Food, Drink \& Tobacco & 15,16 \\
\hline 12 & Textiles, Clothing \& Leather & $17,18,19$ \\
\hline 13 & Paper, Printing \& Publishing & 21,22 \\
\hline 14 & Other Manufacturing & $20,25,36,37$ \\
\hline 15 & Electricity Supply & 40.1 \\
\hline 16 & Gas Supply & $40.2,40.3$ \\
\hline 17 & Water Supply & 41 \\
\hline 18 & Construction & 45 \\
\hline 19 & Wholesale, Vehicle Sales \& Repairs & 50,51 \\
\hline 20 & Retailing & 52 \\
\hline 21 & Hotels \& Catering & 55 \\
\hline 22 & Rail Transport & 60.1 \\
\hline 23 & Road Transport & $60.2,60.3$ \\
\hline 24 & Water Transport & 61 \\
\hline 25 & Air Transport & 62 \\
\hline 26 & Other Transport & 63 \\
\hline 27 & Communications & 64 \\
\hline 28 & Finance & 65,66 \\
\hline 29 & Business Services & $67,70,71,72,73,74$ \\
\hline 33 & Waste Treatment & 90 \\
\hline 34 & Miscellaneous Services & $91-99$ \\
\hline
\end{tabular}


Table 4: U.K Manufacturing Sectors Mark-Ups $(1970-2000)$

\begin{tabular}{|l|l|l|}
\hline No. & Sectors & SIC 92 \\
\hline Non-Durables & 23 \\
\hline 4 & Manufactured Fuel & 24 \\
\hline 5 & Chemical \& Pharmaceuticals & 15,16 \\
\hline 11 & Food, Drink \& Tobacco & $17,18,19$ \\
\hline 12 & Textiles, Clothing \& Leather & 21,22 \\
\hline 13 & Paper, Printing \& Publishing & 26 \\
\hline Durables & 27,28 \\
\hline 6 & Non-Metallic Mineral Products & 29 \\
\hline 7 & Basic Metals \& Metal Goods & $30,31,32,33$ \\
\hline 8 & Mechanical Engineering & 34,35 \\
\hline 9 & Electrical Engineering \& Electronics & $20,25,36,37$ \\
\hline 10 & Vehicles & \\
\hline 14 & Other Manufacturing & \\
\hline
\end{tabular}

\section{The BSVAR Results}

This section commenced by considering the conditional productivity-labour input co-movements and then proceeded to show some evidence based on the bivariate model estimates. It implies that there is more than one quantifiable feature for consideration. The bivariate model results in Table 2 are from the estimated equation (12) using the U.K quarterly data for the period 1971:1 to 2006:4. The baseline series for labour-input is the log of total employee-hours (seasonal adjusted) denoting "hours" and the ONS labours statistics. The result shows an evidence of contractionary effect for the UK economy. In row 1 of Table 5, it implies the unconditional total hours worked declined by 23 percent. With the imposition of long-run restriction, the decline arising due to technology is 55 percent and significant at 5 percent critical level, while that of non-technology is 7 percent and insignificant. This means that most of the shocks are due to technology improvements' impact on hours. When total hours worked is first difference, the effect is a positive outcome, as shown in row 2 of Table 5. All other results in the table gave negative correlation between labour productivity and hours, both on the level and growth rate estimations. Therefore, given the representations, the short-term rigidities in aggregate demand could be due to the stickiness of the price level and as the negative co-movement between productivity and employment (hours) after a technology shock, as also shown in Figure 2. However, in the long-term, there seems to be positive co-movements generated by demand, as shown in Figure 3.

Table 5: Bivariate Estimations (SVAR) - Correlations

\begin{tabular}{|c|c|c|c|}
\hline \multirow{2}{*}{ Estimates } & Unconditional & \multicolumn{2}{|c|}{ Conditional On } \\
\cline { 2 - 4 } & $\operatorname{cor}(\Delta t, \Delta n)$ & $\operatorname{cor}\left(\Delta t, \Delta n / \varepsilon^{z}\right)$ & $\operatorname{cor}\left(\Delta t, \Delta n / \varepsilon^{m}\right)$ \\
\cline { 2 - 4 } & -0.23 & -0.55 & -0.07 \\
\hline \multirow{2}{*}{$\Delta p_{t}, \hat{n}_{t}$ (Total Hours) } & $(-3.14)^{* *}$ & $(-5.01)^{* *}$ & $(-0.74)$ \\
\cline { 2 - 4 }$\Delta p_{t}, \Delta n_{t}$ First Diff & 0.33 & 0.39 & 0.27 \\
\cline { 2 - 4 } & $(3.69)$ & $(1.02)$ & $(1.98)^{* *}$ \\
\hline \multirow{2}{*}{$\Delta p_{t}, \hat{n}_{t}(\mathrm{CE})$} & -0.01 & -0.97 & $(3.34)^{* *}$ \\
\hline \multirow{2}{*}{$\Delta p_{t}, \Delta n_{t}(\mathrm{CE})$} & $(-0.12)$ & $(-3.01)^{* *}$ & -0.47 \\
\cline { 2 - 4 } & -0.48 & -0.49 & $(-2.90)^{* *}$ \\
\hline \multirow{2}{*}{$\Delta p_{t}, \hat{n}_{t}(\mathrm{CLF})$} & $(-5.27)^{* *}$ & $(-1.32)$ & -0.60 \\
\hline \multirow{2}{*}{$\Delta p_{t}, \Delta n_{t}(\mathrm{CLF})$} & -0.04 & -0.70 & $(-0.99)$ \\
\cline { 2 - 4 } & $(-0.49)$ & $(-0.92)$ & -0.54 \\
\hline
\end{tabular}

Data source: ONS-LFS. All estimations are separate regressions. The variable $\hat{n}_{t}$ denotes deviations of log hours from a fitted linear time trend. I then used it in the regressions. The term CE $=$ Hours Civilian Employees. CLF $=$ Hours Civilian Labour force. All the regressions are on first difference respectively. The asterisks (**) denotes significance at $5 \%$ critical value level. The standard errors are in parentheses. Table 4.2 is the estimates of unconditional and conditional correlations between the levels and growth of productivity and labour input (hours or employment) in the UK using quarterly data. 
The unobserved effort variations can also explain the positive co-movement induced by demand shocks. Figure 2 shows the estimated impulse responses based on the model with first difference. In response to a positive technology shock of size equal to Cholesky one-standard deviation, labour productivity indicates an instant increase of about 0.4 percent and subsequently stabilizing at a level higher. Output also experiences a permanent increase, but more gradual than productivity for the de-trended LBHT. The gap between the initial rise in labour productivity and output manifests by a short-term persistent decline in hours.

The negative conditional correlations found in the results are due to the joint variations in employment and productivity coming from technology shock taking place on impact. Under such circumstances, the variables drift into opposite directions, as shown in Figures 2 and 3. As for the positive correlation from the estimated dynamic responses to a non-technology shock, it shows a persistent positive effect on hours and productivity. The impact on hours and output can therefore account for the source of the unit root detected in hours. Equally, the positive comovement of productivity and hours on impact is responsible for the positive sign in the estimated correlation conditional on non-technology shocks. In terms of the appropriateness of the definitions of hours used in Table 5, the results show that $\Delta p_{t}, \Delta n_{t}$ (first differenced hours) estimation is the most preferred. Its expansionary effect is consistent with the RBC models, while others are not. Under the log level hours, it yields a negative impact or contraction. In addition, the result between the two implies that the main intuition is therefore not about the methodological approach, but essentially one of empirical argument. The empirical implication is because hours used in logarithmic levels are trending and therefore require de-trending to achieve stationarity (see Figures 1a and $1 \mathrm{~b}$ and note on Figure 2). Equally, hours in this model gives a better response following positive technology shocks in capturing the dynamic effects in the economy. This is because increases in observed inputs (total hours or hours per worker) can be a proxy for unobserved changes in utilization, such as capacity utilization and labour effort.
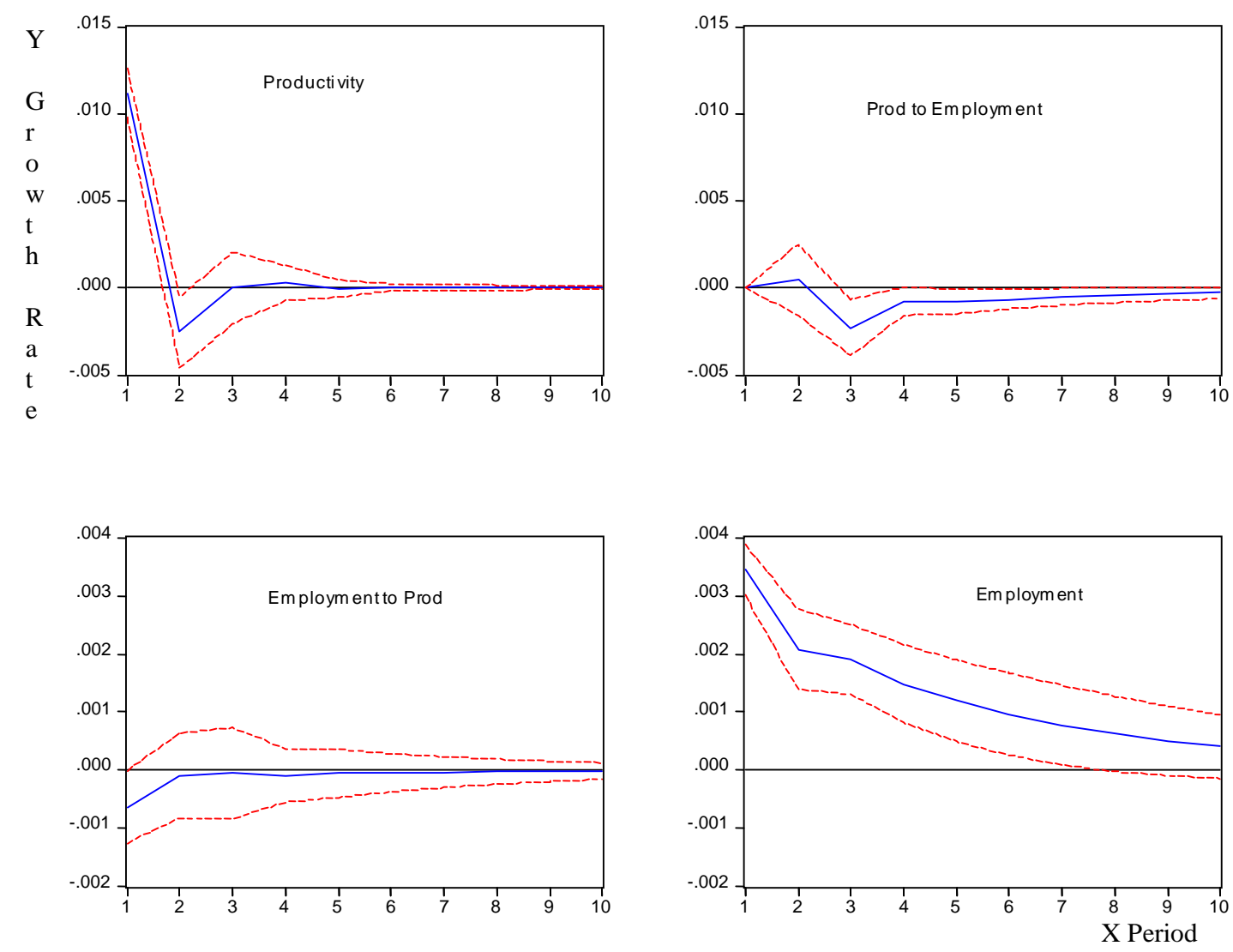

Figure 2: Impulse Responses - Productivity and Employment 

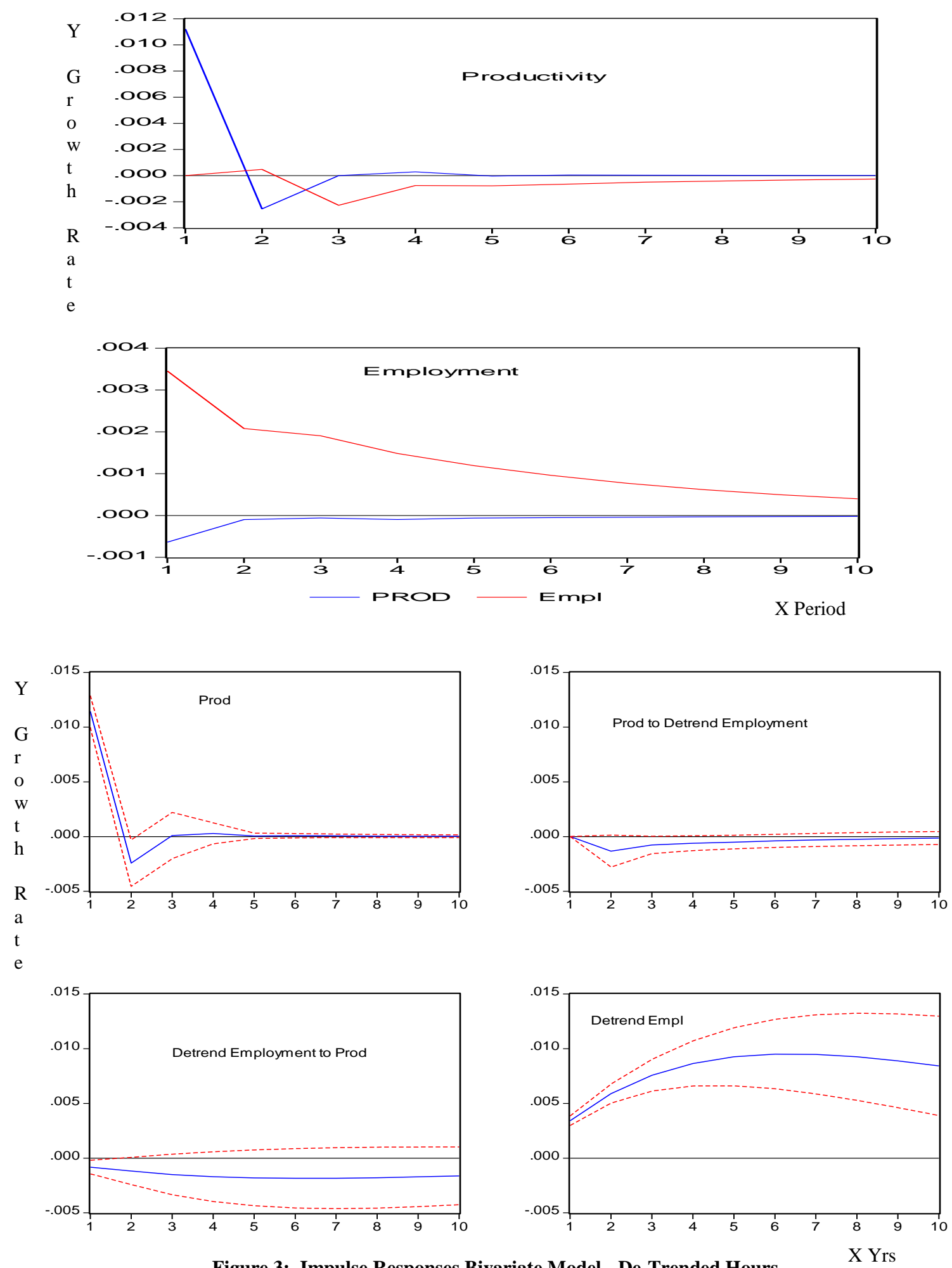

Figure 3: Impulse Responses Bivariate Model - De-Trended Hours 
Table 5 is the conditional correlation estimate for the BSVAR and Table 6, the 5-variable or higher dimension models. The results from the unit root test are for the series used in Table 7. The results from the unit root test are for the series used in the 5-variable model. The null hypothesis for all the series at $5 \%$ test critical values was not rejected.

Table 6: 5-Variable Model - Estimates

\begin{tabular}{|c|c|c|c|}
\hline \multirow{2}{*}{ 5-Var Estimation } & \multirow[b]{2}{*}{ Unconditional } & \multicolumn{2}{|c|}{ Conditional on: } \\
\hline & & Technology & Nontechnology \\
\hline \multirow{2}{*}{$\begin{array}{r}\left.\Delta p_{t} n_{t} \Delta m_{t} r r_{t} \Delta \pi_{t}\right) \\
(\log \text { level hours) }\end{array}$} & 0.02 & 0.01 & 0.02 \\
\hline & $(1.08)$ & $(0.78)$ & $(0.16)$ \\
\hline \multirow{2}{*}{$\begin{array}{r}\left.\Delta p_{t} \Delta n_{t} \Delta m_{t} r r_{t} \Delta \pi_{t}\right) \\
\text { (First-difference hours) }\end{array}$} & 0.16 & -0.02 & 0.31 \\
\hline & $(2.56)^{* *}$ & $(-0.28)$ & $(1.46)$ \\
\hline \multirow{2}{*}{$\left(\Delta p_{t} \Delta n_{t-c e} \Delta m_{t} r r_{t} \Delta \pi_{t}\right)$} & 0.47 & 0.58 & -0.26 \\
\hline & $(6.31)^{* *}$ & $(7.85)^{* *}$ & $(-4.59) * *$ \\
\hline \multirow{2}{*}{$\left(\Delta p_{t} \Delta n_{t-c e} \Delta m_{t} r r_{t} \Delta \pi_{t}\right)$} & 0.44 & 0.56 & -0.60 \\
\hline & $(5.47)^{* *}$ & $(6.96)^{* *}$ & $(-9.53) * *$ \\
\hline \multirow{2}{*}{$\left(\Delta p_{t} \Delta n_{t-} c l \Delta m_{t} r r_{t} \Delta \pi_{t}\right)$} & -0.04 & -0.02 & -0.05 \\
\hline & $(-1.19)$ & $(-0.56)$ & $(-0.32)$ \\
\hline \multirow{2}{*}{$\left(\Delta p_{t} \Delta e m p_{t-} c e \Delta m_{t} r r_{t} \Delta \pi_{t}\right)$} & 0.28 & -0.13 & 0.59 \\
\hline & $(2.15)^{* *}$ & $(-0.39)$ & $(3.68)^{* *}$ \\
\hline \multirow{2}{*}{$\left(\Delta p_{t} \Delta e m p_{t}-c l \Delta m_{t} r r_{t} \Delta \pi_{t}\right)$} & 0.36 & 0.43 & 0.46 \\
\hline & $(3.53) * *$ & $(1.07)$ & $(1.87)^{*}$ \\
\hline
\end{tabular}

Table 6: shows the results from the 5-variable models estimations - unconditional estimation and a decompose technology estimation (technology and non-technology estimates).

Table 7: The Augmented Dickey-Fuller (ADF) Unit Root ADF Test

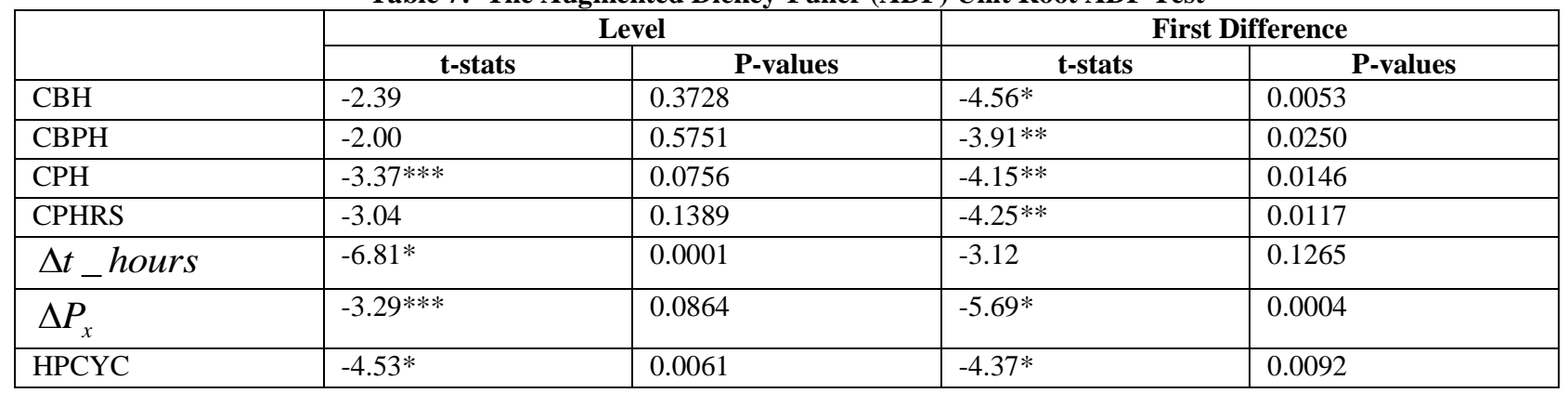

Sources: ONS-LFS and BEID Annual series (1970 - 2000). Test Critical Values: $1 \%$ level $=-4.28,5 \%=-3.56$ and $10 \%=-3.21$.

*Mackinnon (1996) One-Sided p-values

For the first difference estimations, the null hypothesis was rejected. The result indicates that $\left\{\left[P_{t}, n_{t}^{\prime}\right]\right\}$ has integration of order 1 , hence can be written as 1(1). The derivation of null hypothesis from tests using 1(1) is from unit autoregressive root. In cases where 1(1) variable is cointegrating, then this imposes further restrictions on the parameter of the VAR model. It therefore supports the benchmark VAR specification used. In addition, it does not make much difference if hours or employment is used. The results of the unit root tests used in the 5-variable VAR are consistent with the hypothesis of a unit root in the nominal rate $\left(r_{t}\right)$, the growth rate of the money supply $\left(\Delta m_{t}\right)$, and inflation $\left(\Delta \pi_{t}\right)$. The tests do not reject the null that money growth $(\Delta m)$ and inflation $(\Delta \pi)$ are cointegrated with co-integrating vector $[1,-1]$, implying a stationary process for the rate of growth of real balances at 
$10 \%$ level $\left\{\Delta m_{t}-\Delta \pi_{t}\right\}$. For the nominal rate $\left(r_{t}\right)$ and inflation $\left(\Delta \pi_{t}\right)$, the same properties hold, implying a stationary (ex-post) real interest rate process $\left\{r-\Delta \pi_{t+1}\right\}$ or $\left({ }^{r r_{t}}\right)$. This means that the three variables have a single common trend.

\section{Explanation Of The VAR Model}

Sims (1980) proposed a model with a dynamic specification, with the possibility to test causal linkages rather than imposing them, in the form of the vector autoregressive or VAR model. The regressors are lags of all the variables in the model. Since there are no current endogenous variables on the right-hand side of the equation, imposing restrictions on the identifying system is not a feature. The set of regressors is the same for each equation so that each equation is estimated efficiently using the OLS estimator. The VAR model ignored economic restrictions and, as such, 'a theoretic'. It is, on the other hand, a reduced form of simultaneous equations system where the predetermined variables are all lagged dependent variables without pure exogenous variables.

In this case, we have two elements of arbitrariness in specifying the VAR that corresponds to the theory. First, the economic theory does not normally provide indications regarding the lag length of VAR models. Two approaches can be taken in this case: 1) Either a prior chosen lag length and verify that the results are independent of this auxiliary assumption, or 2) to let the data choose the correct lag length using optimal statistical criteria, such as Akaike (1974) or Schwartz (1978).

Secondly, many dynamic models tend to deliver solutions for the vector of endogenous variables with covariance matrix being singular because there are larger numbers of endogenous variables than shocks. Therefore, to undertake a meaningful estimation,one must probabilistically complete the model by adding other sources of disturbances. For example, one possible source for this new disturbance could be a measurement error. In other words, there could be an induce Granger-causality. The concept of Granger causality starts with the premise that the future cannot cause the past. If event A occurs after event B, then A cannot cause B. The Granger causality was applied to economic time series to determine if a particular time series causes another preceding one; in other words, if the set of variables or a variable in one period causes another set of variables or variable. However, merely because event A occurs before B does not mean that A causes B. For example, New Years shopping does not cause a New Year. Granger causality is related to the question of how useful one variable or set of variables $y_{1}$ is for forecasting another variable or set of variables $x_{1}$. If on the other hand, $y_{1}$ does not Granger cause $x_{1}$, then $y_{1}$ does not help to forecast ${ }^{x_{1}}$. For example, if $\mathrm{Y}$ does not cause $\mathrm{X}$ in Granger's definition if, and only if, in the moving average (MA) representation:

$$
\left[\begin{array}{l}
X(t) \\
Y(t)
\end{array}\right]=\left[\begin{array}{l}
a \ldots . b \\
c \ldots . . d
\end{array}\right] *\left[\begin{array}{l}
u \\
v
\end{array}\right](t)
$$

then a or b can be chosen to be identically zero, $v(t)$ is orthogonal to $u(t)$; that is, the residual in a regression. Both $v(t)$ and $u(t)$ are uncorrelated with past values of each other. In addition, $v(t)$ and $u(t)$ are contemporaneously uncorrelated. Equally, when $\left[\begin{array}{l}X \\ Y\end{array}\right]$ has an autoregressive representation, $\mathrm{Y}$ can be expressed as a distributed lag function of current and past $\mathrm{X}$ with a residual that is not correlated with any $\mathrm{X}(\mathrm{s})$, past or future if, and only if, $\mathrm{Y}$ does not cause X in Granger sense (Sims 1972).

Thus, the estimated VAR is non-singular because of omission of important sources of dynamics from the model. Furthermore, the assumption is $\varepsilon_{t}^{z}$ is the first element of ${ }^{e_{t}}$. Therefore, by regressing $u_{t}$ on $\varepsilon_{t}^{z}$ by the 
VAR disturbances gives the computation of the dynamic response of the variables in $Y_{t}$ to $\varepsilon_{t}^{z}$ as the first column of C.

\section{CONCLUSIONS}

The evidence from this study shows that hours worked fall or rise after a positive permanent technology shock, depending on the empirical treatment of hours. The correlation between technology and hours also indicates strong positive co-movements. Similarly, productivity shows positive co-movements with hours because of positive technology shocks. There is clear evidence of contraction following the method advocated by Gali (1999). There is no significant contractionary effect present upon positive technology impact, using direct measure of technology of BFK or the measure proposed by CEV. The specification highlights how permanent technology shock causes a hump-shaped rise in productivity. This implies that the shocks can account for the strong cyclical positive comovements between hours worked and productivity and, as such, it can be concluded that technology shocks are an important impulse factor. The tables reflect the corresponding estimates of productivity-labour input correlations conditional (long-run restriction imposition) on each type of shock. The BSVAR result also shows the unconditional correlations (short-run unrestricted estimation). We presented the results using both $\Delta n_{t}$ and $\hat{n}_{t}$ in the estimated SVAR. The estimates confirm the results from the bivariate model - that technology shocks induce a statistically significant negative correlation between productivity and hours.

The concluding key question here is whether technology shocks do generate recognizable business cycles. As indicated by Gali (1999) and Chang \& Hong (2006), a positive co-movement of GDP and labour input is a key feature of business cycles in industrialized economies. Hence, the answer is affirmative because a positive correlation of output and hours features within the essential predictions of the basic RBC model propelled by technology shocks. It is not explicitly clear if technology shock is responsible for the pattern of GDP and labour input fluctuations associated with business cycles.

Finally, we can conclude that from the results in Table 2, it shows that technology improvements do not contract input use overall. Also very important in this study is the implication for monetary policy given the impact of technology shocks in the model. Monetary policy is crucial for the authorities to determine on how to react to technology shocks in order to adjust to the new level of full employment output. This is not withstanding the fact that monetary policy target is predominately for short-run stabilization of the economy around moving target of full employment output.

It is not explicitly clear if technology shock is responsible for the pattern of GDP and Labor input fluctuations as associated with business cycles; as shown in Figures $4 \mathrm{a}$ and $4 \mathrm{~b}$. The basis for the two figures came from the bivariate VAR. It shows the estimated growth components of GDP and hours, and the two separately. 
Y - Productivity

$\mathbf{X}$ - Period

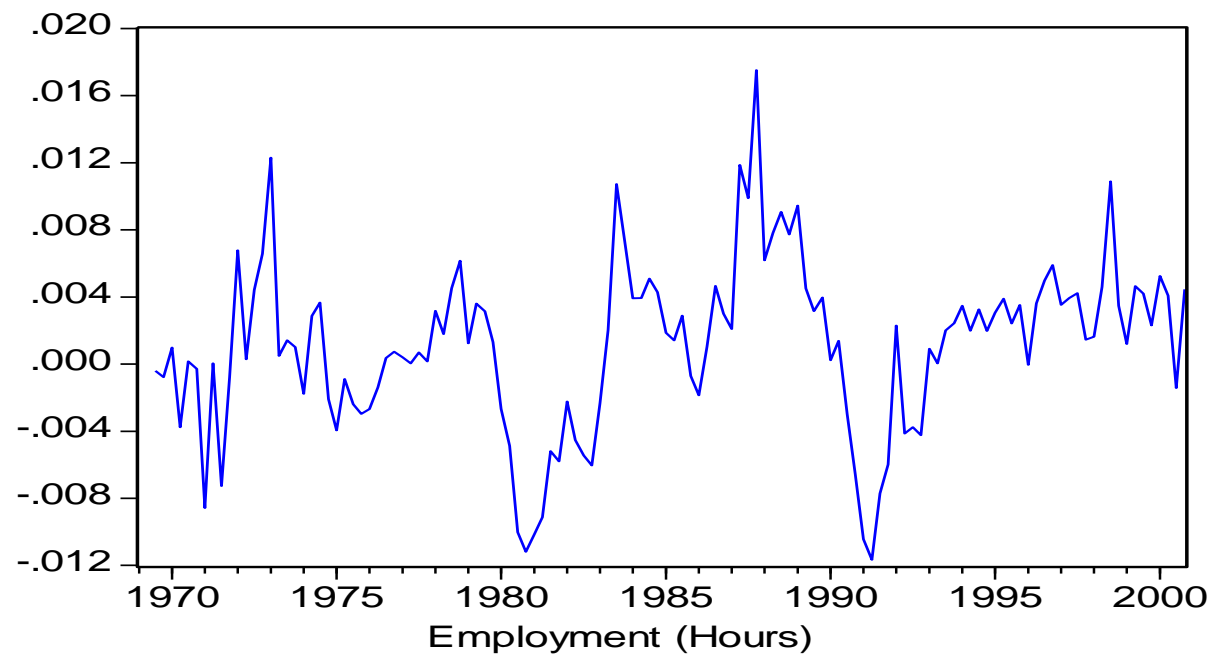

Y - Employment

X - Period

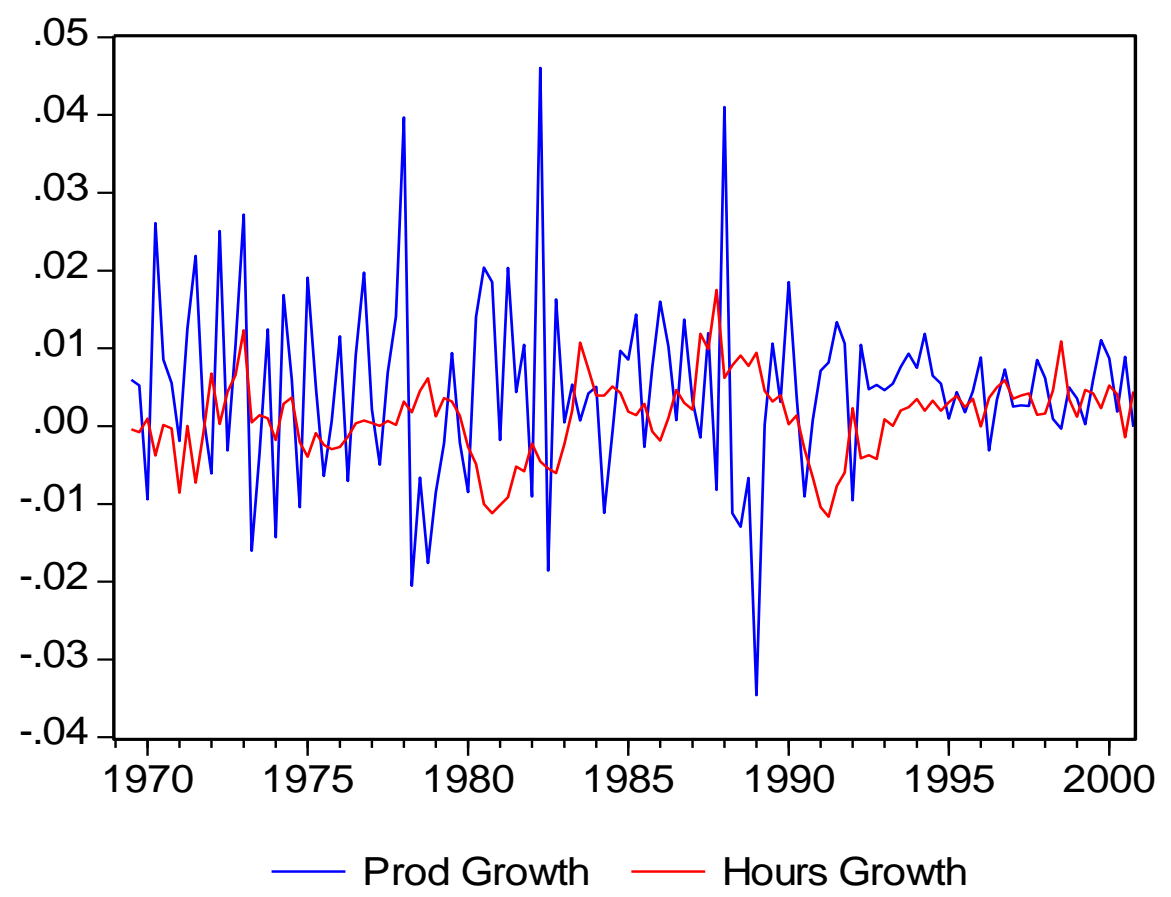

Figure 4a: Estimated Growth Rate Of Productivity And Employment, Respectively 


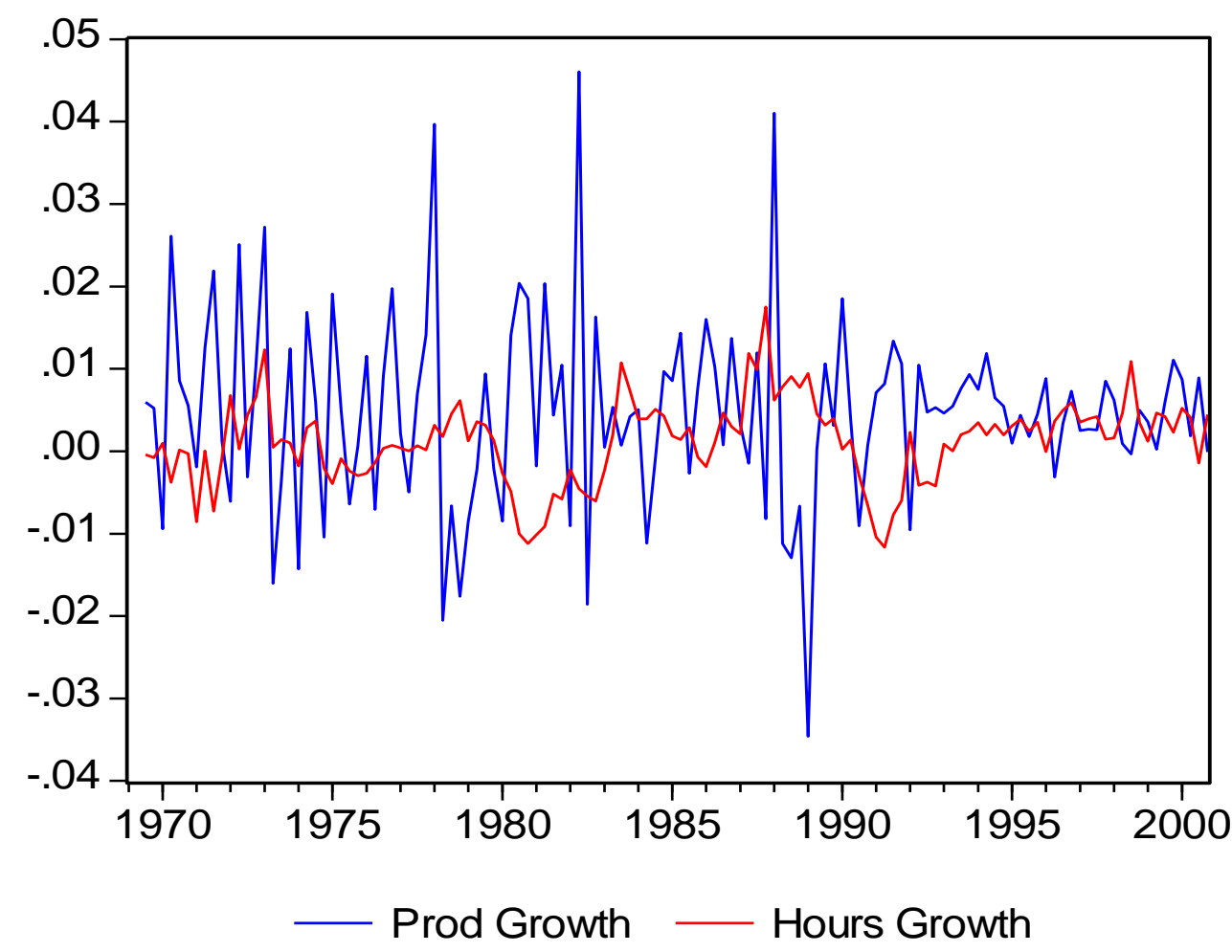

Figure 4b: Combined Estimated Productivity And Employment Growth Rates

\section{ACKNOWLEDGEMENT}

I would like to thank my darling wife, Dr Uzor Guthlac, for her unwavering support and encouragement while I researched for this article.

\section{AUTHOR INFORMATION}

Dr Anyalezu, Nkem. Kirk Guthlac, Faculty, School of Business, University of Phoenix, TeachingApplied/Business/Economics, Ph.D. Economics (University of Surrey, UK), M.Phil. Economics and Political Science (SOAS-University of London, UK), M.Sc. Economics (Birkbeck College-University of London, UK), BA (Combined Hons) Accounting and Economics-(London Metropolitan University, UK), PGC Business Management and Information Technology (Middlesex University, UK), P/Q ACCA (Thames Valley University-UK), MABE, M.Inst.Am, Member-The Royal Economics Society, Associate Member-The Chartered Institute of Bankers, P/Q Member-The Chartered Association of Certified Accountant, Member-The Association of Business Executives.

\section{REFERENCES}

1. Basu, S., Fernald, J., and Kimball, M, 2004, Are Technology Improvements Contractionary? NBER Working Paper Series10592.

2. Basu, S and Fernald, J. G 2002 Aggregate Productivity and Aggregate Technology, European Economic Review 46, 963 - 991.

3. Chang, Y and Hong, J.H, 2006, Do Technological Improvements in the Manufacturing Sector Raise or Lower Employment? The American Economic Review, Vol. 96 No.1, 352 - 368. 
4. Chang, Y and Hong, J.H, 2006, On the Employment Effect of Technology: Evidence from U.S. Manufacturing for 1958 - 1996, Federal Reserve Bank of Richmond Working Paper 03 - 06, 1-32.

5. Christiano, L. J., Eichenbaum, M and Vigfusson, R., 2004, The Response of Hours to a Technology Shock: Evidence Based on Direct Measures of Technology, Journal of the European Economic Association, 2(2 3), $381-95$.

6. Christiano, L.J., Eichenbaum, M and Vigfusson, R., 2003, What Happens After A Technology Shock? NBER Working Paper 9819; Board of Governors of the Federal Reserve System, International Finance Discussion Paper, No. 768, June 2003, 1-52.

7. Francis, N and Ramey, V. A, 2002, Is the technology driven real business cycle hypothesis dead? NBER Working Paper No 8726 (2002).

8. (2004) A New Measure of Hours Per Capita with Implications for the Technology-Hours Debate NBER, 132.

9. Gali, J., 1999, Technology, Employment and the Business Cycle: Do Technology Shocks Explain Aggregate Fluctuations? American Economic Review 89, 249 - 271.

10. Hall, R.E., 1988, The relation between price and marginal cost in U.S. industry. Journal of Political Economy, 96, $921-947$.

11. Hall, R.E., 1990, Invariance properties of Solow's productivity residual, In: Diamond, P. (Ed.), Growth, Productivity, Employment, MIT Press, Cambridge MA.

12. Khan, H and Tsoukalas, J, 2006, Technology Shocks and UK Business Cycles, manuscript.

13. King, R.G., and Rebelo, S. 1999, Resuscitating Real Business Cycles. In Woodford M, and Taylor, J (eds.), Handbook of Macroeconomics, Vol. 1B, Elsevier Science, North-Holland, Amsterdam, p. 927-1007.

14. Kiley, M. T. (1998) Labour Productivity in U.S. Manufacturing: Does Sectoral Comovement Reflect Technology Shocks? Unpublished paper 1998.

15. Marchetti, D. J. and Nucci, F., 2005, Price Stickiness and the Contractionary Effect of Technology Shocks, European Economic Review, 2005, 49(5), 1137 - 1163.

16. Shea, J., 1999, What Do Technology Shocks Do? in Ben S. Bernanke and Julio J Rotemberg, (eds.), NBER Macroeconomics Annual, vol.13, Cambridge, MA: MIT Press, 275 - 310. Also (1998) NBER WP 6632, 1 $-26$.

17. Vigfusson, R.J., 2004, The Delayed Response to Technology Shock,: a Flexible Price Explanation, Board of Governors of the Federal Reserve System, International Finance Discussion Papers, N0. 810, 1 - 44. 
NOTES 